\title{
Study of adverse drug reactions in a tertiary care hospital
}

\author{
Santosh B. Godbharle, Sudhir L. Padwal*
}

Department of Pharmacology, S.R.T.R. Government Medical College, Ambajogai, Maharashtra, India

Received: 03 May 2019

Revised: 25 July 2019

Accepted: 03 August 2019

*Correspondence to:

Dr. Sudhir L. Padwal, Email: drsudhirp.77@gmail.com

Copyright: (C) the author(s), publisher and licensee Medip Academy. This is an openaccess article distributed under the terms of the Creative Commons Attribution NonCommercial License, which permits unrestricted noncommercial use, distribution, and reproduction in any medium, provided the original work is properly cited.

\begin{abstract}
Background: The objectives of the study were to evaluate incidence and preventability of adverse drug events (ADEs) and potential ADEs and to analyse preventable events to develop prevention strategies.

Methods: The study was retrospective observational study conducted at a rural tertiary care hospital at Maharashtra, for 12 months. Patients of both gender and all age group were included in the study. These entire adverse drug reactions were reported either by the PVPI assistance and/or hospital staff and their severity and causality assessments was performed as per Naranjo's and Hartwig's assessment criteria respectively. Data was analyzed by using Microsoft Excel.
\end{abstract}

Results: There were total 256 ADR (adverse drug reactions) were reported in 12 months from January 2018 to December 2018 in various departments of the study center. Most of the adverse drug reactions were reported among age group of 21-40 years patients. Rash and itching (69) were most commonly reported ADR's. ART (31.25\%), antibiotics (28.90\%) were reported to induce maximum number of ADRs. Most of the adverse drug reactions were possible (194, $75.78 \%)$ and mild $(208,81.25 \%)$ in nature.

Conclusions: The antibiotics, ART drugs were most common drugs to reported ADRs. The commonly reported reactions were rash and itching.

Keywords: Adverse drug reaction, Pharmacovigilance, Causality assessment, Naranjo's, Hartwig's assessment, Antibiotics ADR

\section{INTRODUCTION}

Though the drugs are prescribed for the desirable therapeutic effects, but they are not devoid of adverse effects/ side effects and hence drugs should be judicious prescribed considering their likely unwanted harmful effects. An adverse drug reaction (ADR) is defined by the World Health Organization (WHO) as any noxious, unintended, or undesired effect of a drug that occurs at doses used in humans for prophylaxis, diagnosis, or therapy. ${ }^{1}$ Adverse drug reactions take place nearly dayto-day in health care institutions and can affect patient's quality of life, often causing considerable morbidity and sometimes even mortality. ${ }^{2}$
Pharmacovigilance activity has been introduced to monitor and analyses any such unwanted effects of drugs. As per WHO, Pharmacovigilance (PV) is defined as the science and activities relating to the detection, assessment, understanding and prevention of adverse effects or any other drug-related problem. Adverse drug reaction (ADR) are common in the patients who are suffering from severe and complex disease process or are on multiple drugs, leading to possibility of drug-drug interactions.

Multiple factors influence ADR susceptibility, including multiple drug therapy, disease severity, age, and the type and number of drugs prescribed. ${ }^{3}$ Hence attention has been given to recognizing the patient population at risk, 
the drugs most frequently responsible, and the likely causes of ADRs. An upsurge in the number of drugs on the market, an aging population, and an upward trend in polypharmacy are contributing factors to the incidence and prevalence of ADRs worldwide. Adverse drug reactions may lead to loss of belief in or have undesirable feelings toward their doctors and may lead to pursue selfmedication, which may thus increase further ADRs. Around 5\% of all hospital admissions are the result of an ADR, and around $10 \%-20 \%$ of in patients will have at least one ADR during their hospital stay. ${ }^{4}$ The actual incidence of ADRs may be even greater because some ADRs mimic natural disease states and may thus go undetected and/or unreported. Although some ADRs present as minor symptoms, others are serious and cause death in as many as $0.1 \%-0.3 \%$ of hospitalized patients. ${ }^{5}$ Adverse drug reactions should be quickly identified and managed to limit their detrimental effects on the patient. The cost of managing ADRs can be high, whether they occur in the inpatient or the outpatient setting. Because the clinical diagnosis of an ADR is not always obvious, practitioners often order additional laboratory tests or procedures to investigate the cause of a patient's sufferings. 5

Since drugs are intended to relieve suffering, patients find it particularly offensive that they can also cause disease. It has been reported that ADRs account for 5\% of all hospital admissions and occur in 10-20\% of hospitalized patients. $^{6}$ An overall incidence of serious and fatal ADR among hospitalized patients is $6.7 \%$ and $0.32 \%$, respectively. Sometimes, ADR-related costs, such as hospitalization, surgery and lost productivity, exceed the cost of the medications. ${ }^{4}$ The recent epidemiological studies have estimated that adverse drug reactions are the fourth to sixth leading causes of death. ${ }^{7}$ Moreover, detection of ADRs has become increasingly significant because of introduction of a large number of potent toxic chemicals as drug in last two or three decades. Thus, it became very crucial to monitor both known and unknown adverse effects of medicines.

Though ADRs are of great concern to the general public, medical profession, pharmaceutical industry and regulatory authorities, the concept of ADR reporting is still new in India and reporting of ADRs is infrequent. Govt. of India under the guidance of Ministry of Health and Family Welfare has initiated an ADR reporting program known as Pharmacovigilance Program of India and has established adverse drug reaction monitoring centers in various tertiary care hospitals across the country to monitor ADRs. ${ }^{8}$ However, from this region still there is underreporting of ADRs. Hence, this study was undertaken to record and analyze adverse drug reactions reported from various departments of a tertiary care hospital situated at Rural Medical College, Maharashtra. We have also analyzed ADRs for causality and severity.

\section{METHODS}

An observational, cross-sectional study was carried out for 12 months from January 2018 to December 2018 at a Rural Medical college and Hospital in Maharashtra, India. ADRs were reported from outpatient departments as well as from wards of cardiology, dermatology, gynaecology, medicine, ophthalmology, paediatric, psychiatry, TB and chest, and neurology department of the hospital. Those cases which were identified and reported by physicians of this hospital were considered as an ADR and recorded. The collected information included patient's initial, age, gender, reporting department of the hospital, description of the reaction, duration of reaction, name of the suspected drug causing reaction, and outcomes. Drugs causality assessment was performed by Naranjo's probability assessment scale and Hartwig's criterion was used for severity assessment., ${ }^{9,10}$ Attempt of Rechallenge was not found in any patient. Outcome of the patients with ADR were recorded as fatal, fully recovered (patient fully recovered during study period), recovering (patient recovering, but not fully recovered during study period) and unknown (insufficient information and not documented).

\section{Inclusion criteria}

All the suspected ADRs that may be due to the medications, both prescribed and over the counter, taken by patients either as inpatients or outpatients, that were ultimately noted.

\section{Exclusion criteria}

The use of alternative system of medicines such as Ayurveda, Homeopathy, Unani, etc. as well as over prescribing, over dosage, excess consumption and patients taking more than ten prescription drugs were excluded. All mentally retarded, drug addicted, and unconscious patients were also excluded from the study. Patients admitted due to alcohol or drug abuse, a suicide attempt or admissions planned more than $24 \mathrm{~h}$ in advance were not recorded. Naranjo ADR probability scale for causality assessment.

\section{Statistical analysis}

Description statistics were used for data analysis with the help of Microsoft Excel.

\section{RESULTS}

In this study, 256 patients were reported to experience ADR during study period. Most of the patients $(52.37 \%)$ were reported from in-patient departments and rests $(47.63 \%)$ were reported from outpatient department of the hospital. The mean age of the patients was 35.56 years; youngest patient was of 1 year 6 months and oldest being 81 years. Majority of the patients $(55.07 \%)$ experienced ADRs belonged to age group of 21-40 years (Figure 1). 
Out of 256 patients, $122(47.64 \%)$ patients were male while $134(52.36 \%)$ patients were female as shown in Table 1.

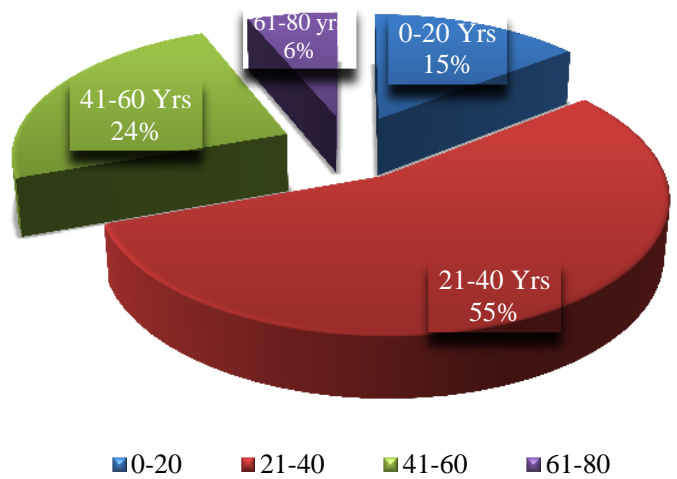

Figure 1: Age distribution of patients with ADRs.

Table.1 Gender distribution in study population.

\begin{tabular}{|lll|}
\hline Gender & Number & Percentage $(\%)$ \\
\hline Male & 122 & 47.65 \\
\hline Female & 134 & 52.34 \\
\hline
\end{tabular}

Table 2: Types of ADRs.

\begin{tabular}{|lll|}
\hline $\begin{array}{l}\text { Skin rash/ Itching / } \\
\text { Hypersensitivity }\end{array}$ & 69 & 34.37 \\
\hline Swelling (local area) & 18 & 7.03 \\
\hline Anemia & 17 & 6.64 \\
\hline Diarrhea & 16 & 6.25 \\
\hline Fever & 7 & 2.73 \\
\hline Dizziness & 6 & 2.34 \\
\hline $\begin{array}{l}\text { Steven Jonson } \\
\text { syndrome }\end{array}$ & 2 & 0.78 \\
\hline Breathlessness & 2 & 0.78 \\
\hline Others & 100 & 39.06 \\
\hline
\end{tabular}

In this study, $256 \mathrm{ADRs}$ were reported from various departments of the hospital. Of all reported ADRs, most common ADR was rash and itching / Hypersensitivity $(34.37 \%)$ and followed by local swelling $(7.03 \%)$. (Table. 2) The antibiotics and antiretroviral (ART) was most common drugs reported to causing ADRs, as shown in Figure 2. Skin was the most commonly affected organ system $(54.32 \%)$.

Table 3: Causality assessment of ADRs.

\begin{tabular}{|lll|}
\hline Types & Number & Percentage (\%) \\
\hline Probable & 194 & 75.78 \\
\hline Possible & 28 & 10.93 \\
\hline Definite & 32 & 12.50 \\
\hline
\end{tabular}

According to the Naranjo's algorithm scale, 194 (75.78\%) assumed ADRs were probable, 28 (10.93\%) ADRs were reported as possible and $32(12.50 \%)$ ADRs were reported as definite (Table 3). According to Hartwig severity assessment scale, most of the ADRs were mild $208(81.25 \%)$, moderate $26(10.15 \%)$ and $20(7.81 \%)$ ADR report was severe (Table 4). Most of the patients with ADRs 251 (98.04\%) were completely recovered after treatment and $5(1.96 \%)$ ADRs had lost to follow up hence their outcome was unknown.

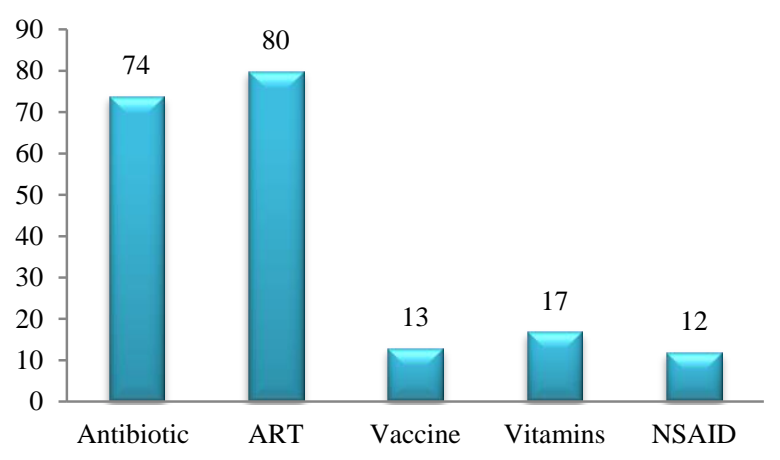

$\square$ Number of ADR Patients

Figure 2: Class of drugs causing ADRs.

Table 4: Severity assessment of ADRs.

\begin{tabular}{|lll|}
\hline Severity & Number & Percentage (\%) \\
\hline Severe & 20 & 7.81 \\
\hline Moderate & 26 & 10.15 \\
\hline Mild & 208 & 81.25 \\
\hline
\end{tabular}

\section{DISCUSSION}

In this study, 256 ADRs were reported during study period. Most commonly it occurred in age group of 21-40 years. Though, elderly patients are more prone to ADRs but in this study ADRs were reported in younger age group as it is likely that this population was attending hospital more frequently to study center. Elderly predisposes to ADRs due to changed pharmacokinetics and pharmacodynamics, co-morbidity from chronic diseases, disease burden, severity of illness, polypharmacy and use of inappropriate drugs. ${ }^{11}$ It has been observed in this study that ADRs were more common in females as compared to males. Majority of ADRs were reported from female patients than from male. The female gender was associated with higher risk of ADRs than male. ${ }^{12,13}$ Similar results have been reported by Singh et al were $67.67 \%$ of study population of ADRs was females. ${ }^{14}$

But as per previous study by Priyadharsini et al and Mandavi et al, ADRs are most commonly seen in Pediatric and geriatric group of patients as they are susceptible groups for ADR more frequently. But the result of our study does not match with these studies. ${ }^{15,16}$ 
Most of the ADRs were reported from Medicine department and ART center this might be due to the increasing awareness among physicians regarding ADR reporting. Similar kind of results were reported from previous study Shamna et al and Lihite et al. ${ }^{17,8}$

In this study, rash and itching, hypersensitivity reaction, local swelling, anemia, diarrhea were commonly reported ADRs. Steven Jonson syndrome (SJS) is rare but potentially life threatening serious ADR which was also reported in our study, although in two patients but as it life threatening reaction patients were treated accordingly on priority basis with final outcome of complete recovery and no mortality.

In our study, majority of the ADRs were associated with ART drugs and antibiotics drugs. Similar results were obtained by study done by Singh et al and Laskar et al were antibiotics commonly associated with adverse drug reaction. $^{14,18}$ As per analysis of data obtained most of reported ADRs were probable $75.78 \%$, followed by definite $12.50 \%$ and possible was $10.93 \%$. As per Hartwig criteria most of the ADR reports were mild in nature and recovered during study period. These findings are similar to the previous studies done by Arulmani et al and Shrivastava et al. ${ }^{19,20}$

\section{Limitations}

This study suffers the main drawback of spontaneous reporting system i.e. underreporting. Thus, ADR monitoring should be strengthened in this diversified region by sensitizing and encouraging healthcare providers to report ADRs.

\section{CONCLUSION}

The Antimicrobials, antibiotics and ART drugs were reported to cause majority of ADRs in this tertiary care center. The commonly reported ADR in this study was rash and itching. This study suggests that there is a need of spontaneous ADR reporting from all the departments of this tertiary care hospital for monitoring and assessment of ADRs. This study also warrants further research in this part of India for the development of possible intervention strategies to reduce burden of ADRs. Present study revealed that, more awareness about the importance of Pharmacovigilance have to be provided among the health care professionals by way of ADR bulletins, seminars and workshops. Also, more studies with comprehensive sample size need to be conducted in Indian population to know the exact incidence and prevalence of ADRs.

\section{Funding: No funding sources}

Conflict of interest: None declared

Ethical approval: The study was approved by the Institutional Ethics Committee

\section{REFERENCES}

1. World Health Organisation: International drug monitoring: the role of the hospital. In Technical report series no. 425. Geneva, Switzerland: World Health Organization; 1966: 1-24.

2. Juntti. PL, Neuvoren PJ. Drug-related deaths in a university central hospital. Eur J Clin Pharmacol. 2002;58:479-82.

3. Lobo MGAA, Pinheiro SMB, Castro JSD, Momenté VG, Pranchevicius MCS. Adverse drug reaction monitoring: support for pharmacovigilance at a tertiary care hospital in Northern Brazil. BMC Pharmacol Toxicol. 2013;14(5):1-7.

4. Kongkaew C, Noyce PR, Ashcroft DM. Hospital admissions associated with adverse drug reactions: a systematic review of prospective observational studies. Ann Pharmacother. 2008;42:1017-25.

5. Lazarou J, Pomeranz BH, Corey PN. Incidence of adverse drug reactions in hospitalized patients. JAMA. 1998;279:1200-5.

6. Einarson TR. Drug-related hospital admissions. Ann Pharmacother. 1993;27:832-84.

7. Srinivasan R, Ramya G. Adverse drug reaction causality assessment. Int J Res Pharm Chem. 2011;1(3):606-11.

8. Lihite R. Lahkar M. An update on pharmacovigilance programme of India. Front Pharmacol 2015; 6:194.

9. Naranjo CA, Busto U, Sellers EM, Sandor P, Ruiz I, Roberts EA, et al. A method for estimating the probability of adverse drug reactions. Clin Pharmacol Ther. 1981;80:289-95.

10. Hartwig SC, Siegel J, Schneider PJ. Preventability and severity assessment in reporting adverse drug reactions. Am J Hosp Pharm. 1992;49;2229-32.

11. Alomar MJ. Factors affecting the development of adverse drug reactions. Saudi Pharm J. 2014;22(2):83-94

12. Jose J, Padma GM, Beena J. Adverse drug reactions to fluoroquinolone antibiotics - analysis of reports received in a tertiary care hospital. Int $\mathbf{J}$ Risk Saf Med. 2008;20:169-80.

13. Krahenbuhl MA, Schlienger R, Lampert M, Haschke M, Drewe J, Krähenbühl S. Drug related problems in hospitals: a review of the recent literature. Drug Saf 2007;30(5):379-407

14. Singh P. Adverse drug reactions at adverse drug reaction monitoring center in Raipur: Analysis of spontaneous reports during 1 year. Indian $\mathrm{J}$ Pharmacol. 2017;49:432-7.

15. Priyadharsini R, Surendiran A, Adithan C, Sreenivasan S, Sahoo FK. A study of adverse drug reactions in pediatric patients. J Pharmacol Pharmacother. 2011;2:277-80.

16. Mandavi DS, Sachdev A, Tiwari P. Adverse drug reactions \& their risk factors among Indian ambulatory elderly patients. Indian J Med Res. 2012;136:404-10.

17. Shamna M, Dilip C, Ajmal M, Linu Mohan P, Shinu C, Jafer CP, et al. A prospective study on Adverse 
Drug Reactions of antibiotics in a tertiary care hospital. Saudi Pharm J. 2013;22:303-8.

18. Laskar J, Chakravarty P, Dewan B. A study on incidence of adverse drug reactions with commonly prescribed drugs and causality assessment in Silchar Medical College and Hospital. Int $\mathbf{J}$ Basic Clin Pharmacol. 2017;6(5):1175-83.

19. Arulmani R, Rajendran SD, Suresh B. Adverse drug reaction monitoring in a secondary care hospital in South India. Br J Clin Pharmacol. 2008;65:210-6.
20. Shrivastava M, Uchit G, Chakravarti A, Joshi G, Mahatme M, Chaudhari H. Adverse drug reactions reported in Indira Gandhi Government Medical College and Hospital, Nagpur. J Assoc Physicians India. 2011;59:296-9.

Cite this article as: Godbharle SB, Padwal SL. Study of adverse drug reactions in a tertiary care hospital. Int J Basic Clin Pharmacol 2019;8:2013-7. 